\title{
Assessment of the beneficial loci and prognostic implications of microsatellite instability in gastric carcinoma
}

\author{
JI UN KANG ${ }^{1}$ and SUN HOE KOO ${ }^{2}$ \\ ${ }^{1}$ Department of Biomedical Laboratory Science, Korea Nazarene University, Cheonan 331-718; \\ ${ }^{2}$ Department of Laboratory Medicine, Chungnam National University \\ College of Medicine, Taejeon 301-721, Republic of Korea
}

Received April 1, 2011; Accepted July 18, 2011

DOI: $10.3892 / \mathrm{mmr} .2011 .541$

\begin{abstract}
Microsatellite instability (MSI) is a hyper-mutable phenotype caused by the loss of DNA mismatch repair activity, and plays a crucial role in gastric carcinogenesis. To clarify the role of genetic instability in relation to clinicopathological variables, and to identify predictive MSI markers that facilitate the early detection and improve the classification of gastric carcinomas (GCs), 13 microsatellite (MS) loci, including the National Cancer Institute (NCI) panel of MS markers (D2S123, D5S346, D17S250,BAT25 and BAT26) and 8 dinucleotide repeats $(D 3 S 1260, D 5 S 107, D 5 S 409, D 17 S 261$, D17S520,D17S855,D18S34 and D18S61) were studied in GC patients. MSI was found in $88.2 \%$ (30/34) of GC cases and the number of high-frequency MSI (MSI-H, 23.5\%, 8/34), low-frequency MSI $(64.7 \%, 22 / 34)$, and stable MSI (11.8\%, $4 / 34$ ), was calculated. Among the MS loci analyzed, D18S34 and $D 17 S 261(15 / 34,44.1 \%)$ exhibited the highest frequency of MSI, followed by D2S123 (14/34, 41.2\%), D5S107, D5S346, D5S409 and D18S61 (12/34, 35.3\%) (MSI $>35 \%)$. MSI-H was particularly prevalent in older patients and was mainly found in the antrum and poorly differentiated tumors. Furthermore, MSI-H was significantly associated with lymph node involvement cases in females. One notable finding in this analysis was that the markers, D17S250 and D17S520, exhibited a significantly higher percentage of MSI in advanced gastric carcinomas than in early gastric carcinomas $(\mathrm{P}=0.046$ and 0.046 , respectively), and the D17S520 and BAT26 loci represented significant different correlations between the tumor stages ( $\mathrm{P}=0.038$ and 0.042 , respectively). This study indicates that the novel markers, D18S34 and D17S261, perform more favorably than the NCI panel for the detection of MSI, and the D17S520 locus presents a potential target for predicting the clinical impact of GC. These novel MS loci may prove to
\end{abstract}

Correspondence to: Sun Hoe Koo, Chungnam National University Hospital, 640 Daesadong, Jung-Gu, Taejeon 301-721, Republic of Korea E-mail: shkoo@cnu.ac.kr

Key words: gastric carcinoma, microsatellite instability, clinicopathological variables be beneficial and independent tools for the construction of a comprehensive genetic classification for GC cases.

\section{Introduction}

Gastric carcinoma (GC) is responsible for the highest number of cancer-related deaths worldwide (1). Genetic instability in GC represents a key molecular step that occurs early in the carcinogenesis process $(2,3)$. Although numerous studies have been performed to evaluate the genetic events associated with the development and progression of GC $(4,5)$, its molecular mechanism still remains to be understood, and identification of the predictive markers is crucial.

Microsatellite instability (MSI) is a phenomenon caused by a mismatch repair gene deficiency, and plays an important role in the development and progression of tumor cells. The detection of the MSI frequencies or the degrees of the MSI at the specific microsatellite (MS) loci in the tumors might reveal the presence of DNA mismatch repair genes, which may be used as a prognostic indicator of GC (6).

Previous studies (2-5) have revealed that colorectal cancers exhibit distinctive clinicopathological characteristics and prognoses according to the MSI status. However, there is a wide variation in results between MSI status and clinicopathological parameters in GCs due to a lack of standardized and comparable parameters (7). Although the potential of MSI as a molecular prognostic marker in GC has gained prominence over the years, most reports in the literature are prone to arbitrariness, and the potential limitations of the National Cancer Institute (NCI)-recommended panel of MS markers for MSI testing have been recognized (8-11).

In this study, we therefore examined the 13 MS loci, including the NCI panel of MS markers and 8 additional dinucleotide repeats scattered over 7 chromosome arms $(2 p$, $3 p, 4 q, 5 q, 17 p, 17 q$ and 18q) to assess the frequency of MSI at various genomic loci according to clinicopathological parameters, and to identify predictive MSI markers that facilitate the early detection or improved classification of GC.

\section{Materials and methods}

Patient specimens. The paraffin-embedded tissues from 7 early gastric carcinomas (EGCs) and 27 advanced gastric 
Table I. MS loci analyzed in GCs.

\begin{tabular}{|c|c|c|c|}
\hline Locus symbol & Chromosome & Gene & Sequence $\left(5^{\prime} \rightarrow 3^{\prime}\right)$ \\
\hline $\mathrm{D} 2 \mathrm{~S} 123$ & $2 \mathrm{p} 21-2 \mathrm{p} 16$ & hMSH2 & $\begin{array}{l}\text { 5'-6FAMAAACAGGATGCCTGCCTTTA-3' } \\
\text { 5'-GGACTTTCCACCTATGGGAC-3' }\end{array}$ \\
\hline D3S1260 & $\begin{array}{l}3 \mathrm{p} 23-3 \mathrm{p} 21 \\
3 \mathrm{p} 24.2-3 \mathrm{p} 22\end{array}$ & & $\begin{array}{l}\text { 5'-AGCTACCAGGGAAGCACTGT-3' } \\
\text { 5'-CTATGCAATCACCTGCCATT-3' }\end{array}$ \\
\hline D5S107 & $5 q 11.2-5 q 13.3$ & $A P C / M C C$ & $\begin{array}{l}\text { 5'-6FAMGATCCACTTTAACCCAAATAC-3' } \\
\text { 5'-GGCATCAACTTGAACAGCAT-3' }\end{array}$ \\
\hline D5S346 & $5 q 21-5 q 22$ & $A P C$ & $\begin{array}{l}\text { 5'-ACTCACTCTAGTGATAAATCGGG-3' } \\
\text { 5'-AGCAGATAAGACAGTATTACTAGTT-3' }\end{array}$ \\
\hline D5S409 & $\begin{array}{l}5 \mathrm{q} 14-5 \mathrm{q} 15 \\
5 \text { pter-5qter }\end{array}$ & & $\begin{array}{l}\text { 5'-6FAMGGGATGAAGTGTGGATAAAC-3' } \\
\text { 5'-TAGGATGGCAGTGCTCTTAG-3' }\end{array}$ \\
\hline $\mathrm{D} 17 \mathrm{~S} 250$ & 17q11.2-17q12 & & $\begin{array}{l}\text { 5'-GGAAGAATCAAATAGACAAT-3' } \\
\text { 5'-GCTGGCCATATATATATTTAAACC-3' }\end{array}$ \\
\hline D17S261 & $17 \mathrm{p} 12-17 \mathrm{p} 11.2$ & & $\begin{array}{l}\text { 5'-CAGGTTCTGTCATAGGACTA-3' } \\
\text { 5'-TTCTGGAAACCTACTCCTGA-3' }\end{array}$ \\
\hline D17S520 & $17 \mathrm{p} 12-17 \mathrm{p} 12$ & Tp53 & $\begin{array}{l}\text { 5'-6FAMGTACTGGGCCTCTAAACTCTA-3' } \\
\text { 5'-TTAGGAGAAAGTGATACAAGG-3' }\end{array}$ \\
\hline D17S855 & $17 q-17 q$ & & $\begin{array}{l}\text { 5'-GGATGGCCTTTTAGAAAGTGG-3' } \\
\text { 5'-ACACAGACTTGTCCTACTGCC-3' }\end{array}$ \\
\hline D18S34 & $18 \mathrm{q} 12.2-18 \mathrm{q} 12.3$ & $D C C$ & $\begin{array}{l}\text { 5'-6FAMCAGAAAATTCTCTCTGGCTA-3' } \\
\text { 5'-CTCATGTTCCTGGCAAGAAT-3' }\end{array}$ \\
\hline D18S61 & $18 \mathrm{q} 22.3-18 \mathrm{q} 22.3$ & & $\begin{array}{l}\text { 5'-ATTTCTAAGAGGACTCCCAAACT-3' } \\
\text { 5'-ATATTTTGAAACTCAGGAGCAT-3' }\end{array}$ \\
\hline BAT25 & $4 q 12-4 q 12$ & $c$-kit & $\begin{array}{l}\text { 5'-TCGCCTCCAAGAATGTAAGT-3' } \\
\text { 5'-TCTGGATTTTAACTATGGCTC-3' }\end{array}$ \\
\hline BAT26 & $2 \mathrm{p} 16-2 \mathrm{p} 16$ & hMSH2 & $\begin{array}{l}\text { 5'-TGACTACTTTTGACTTCAGCC-3' } \\
\text { 5'-AACCATTCAACATTTTTAACC-3' }\end{array}$ \\
\hline
\end{tabular}

carcinomas (AGCs) were obtained from the Chungnam National University Hospital (Taejeon, Republic of Korea). The patients were classified according to the WHO histological typing of gastric tumors and the UICC tumor-node-metastasis (TNM) staging system. All cases were reviewed by pathologists to verify the original histopathological diagnosis, tumor stage, tumor differentiation, and lymph node metastasis.

The neoplastic and adjacent non-neoplastic areas were microdissected individually. The genomic DNA was extracted using a genomic DNA purification kit (Promega, Madison, WI, USA), with some modifications as previously described (12). This study was reviewed and approved by the Institutional Review Board of the Chungnam National University Hospital. Written informed consent was obtained from each patient according to the institutional regulations.

Polymerase chain reaction (PCR). A total of $20 \mu \mathrm{l}$ of the PCR mixture (AmpliTaq Gold PCR master mix, Applied Biosystems, Foster City, CA, USA) containing $50 \mathrm{ng} / \mu \mathrm{l}$ of the DNA template was prepared for a 30-cycle amplification. The optimal conditions for each primer to react were selected in order to avoid the formation of multiple artifacts as previously reported (13).

The reaction was performed in an automated GeneAmp PCR thermal cycler (Perkin Elmer, Waltham, MA, USA). The thermocycling was programmed as follows: denaturation at $95^{\circ} \mathrm{C}$ for $10 \mathrm{~min}$ in the early stage and at $96^{\circ} \mathrm{C}$ for $10 \mathrm{sec}$ in the late stage followed by annealing at an optimally conditioned temperature for $30 \mathrm{sec}$, extension at $70^{\circ} \mathrm{C}$ for $3 \mathrm{~min}$, and 30 min only in the last cycle.

MSI analysis. Matched tumor and normal tissue samples from 34 GC patients were analyzed using 13 MS loci with an ABI Genetic Analyzer (Applied Biosystems). The reaction mixture for electrophoresis was composed of $0.3 \mu \mathrm{l}$ of the PCR product, $0.5 \mu \mathrm{l}$ of the Genescan size standard, and $14.2 \mu \mathrm{l}$ formamide (Applied Biosystems). The samples were then injected for capillary electrophoresis. The electrophoresis was confirmed with a log file, set using Genescan software (Applied Biosystems) and calculated by the Genotype software. MSI was evident when the tumor DNAs exhibited new bands compared to their normal counterparts. Genomic DNA from K562 cells and nuclease-free water were used as positive and negative controls, respectively.

MSI was classified as an MSI genotype based on the ratio of the number with a positive MSI to the total number of examined MS loci. Cases that were MSI-positive $\left(\mathrm{MSI}^{+}\right)$ in $\geq 40 \%$ of the tested markers were designated as highfrequency MSI (MSI-H), and cases that were $\mathrm{MSI}^{+}$in $<40 \%$ of the tested markers were designated as low-frequency MSI 


\begin{tabular}{|c|c|c|c|c|c|c|c|c|c|c|c|c|c|}
\hline $\begin{array}{l}C_{0.50} \\
\text { Ito. }\end{array}$ & D2s233 & DS53 36 & D17s250 & 34525 & 34726 & D351260 & DS5:07 & DSS 409 & D1/S363 & DI7ss20 & Diysoss & DISSA & DISS62 \\
\hline 1 & & & & & & & & & & & & & \\
\hline 2 & & & & & & & & & & & & & \\
\hline 3 & & & & & & & & & & & & & \\
\hline 4 & & & & & & & & & & & & & \\
\hline 5 & & & & & & & & & & & & & \\
\hline 6 & & & & & & & & & & & & & \\
\hline 7 & & & & & & & & & & & & & \\
\hline 8 & & & & & & & & & & & & & \\
\hline 9 & & & & & & & & & & & & & \\
\hline 10 & & & & & & & & & & & & & \\
\hline 11 & & & & & & & & & & & & & \\
\hline 12 & & & & & & & & & & & & & \\
\hline 13 & & & & & & & & & & & & & \\
\hline 14 & & & & & & & & & & & & & \\
\hline 15 & & & & & & & & & & & & & \\
\hline 16 & & & & & & & & & & & & & \\
\hline 17 & & & & & & & & & & & & & \\
\hline 18 & & & & & & & & & & & & & \\
\hline 19 & & & & & & & & & & & & & \\
\hline 20 & & & & & & & & & & & & & \\
\hline 21 & & & & & & & & & & & & & \\
\hline$\overline{22}$ & & & & & & & & & & & & & \\
\hline 23 & & & & & & & & & & & & & \\
\hline 24 & & & & & & & & & & & & & \\
\hline 25 & & & & & & & & & & & & & \\
\hline 26 & & & & & & & & & & & & & \\
\hline 28 & & & & & & & & & & & & & \\
\hline 29 & & & & & & & & & & & & & \\
\hline 30 & & & & & & & & & & & & & \\
\hline 31 & & & & & & & & & & & & & \\
\hline 32 & & & & & & & & & & & & & \\
\hline 33 & & & & & & & & & & & & & \\
\hline 34 & & & & & & & & & & & & & \\
\hline
\end{tabular}

Figure 1. A graphic representation of the MSI frequencies from 13 MS markers. The status of each MS locus is indicated as follows: gray, MSI positive; white, MSI negative.

(MSI-L) (14-16). A non-detectable MSI was assessed as stable MSI (MSS).

Statistical analysis. Associations between clinicopathological features and the degree of MSI were analyzed using either the Chi-square test or the one-way ANOVA test. P-values correspond to two-sided tests. Differences were considered statistically significant if $\mathrm{P}<0.05$. Calculations were performed using the 13.0 SPSS software package.

\section{Results}

MSI analysis. MSI was assessed by comparison of paired tumor and normal samples using 13 MS loci including the 5 NCI panel of markers (D2S123, D5S346, D17S250, BAT25 and $B A T 26)$ and 8 dinucleotide repeats (D3S1260, D5S107, D5S409, D17S261, D17S520, D17S855, D18S34 and D18S61) using an ABI PRISM Genetic Analyzer. The primers for the 13 MS markers are presented in Table I.

The 13 MS markers were successfully amplified in samples from the GC cases. The presence of unequivocal changes when compared to the matching normal samples (shifts in fragments and appearance of new peaks) was classified as MSI. The overall frequency of $\mathrm{MSI}^{+}$cases (allelic shifts in at least one marker) was $88.2 \%$ (30/34) with a range from $23.5 \%$ to $44.1 \%$ on each locus. Fig. 1 shows a graphic representation of the MSI frequencies from 13 different MS markers.

Among the NCI panel of MS loci analyzed, D2S123 $(41.2 \%, 14 / 34)$ presented the most frequently altered target of MSI, followed by D5S346 (35.3\%, 12/34), D17S250 (32.4\%, 11/34), BAT25 (26.5\%, 9/34) and BAT26 (23.5\%, 8/34). Among the 8 dinucleotide panels, D18S34 and D17S261 exhibited the highest polymorphic rate at $44.1 \%(15 / 34)$, followed by D5S107, D5S409 and D18S61 (35.3\%, 12/34), 
Table II. The correlation between MSI status and clinicopathological variables in GCs.

\begin{tabular}{|c|c|c|c|c|c|c|}
\hline Variable & $\begin{array}{l}\text { MSS } \\
(n=4)\end{array}$ & $\begin{array}{l}\text { MSI-L } \\
(n=22)\end{array}$ & $\begin{array}{c}\text { MSI-H } \\
(n=8)\end{array}$ & $\begin{array}{c}\text { Total }(\%) \\
(n=34)\end{array}$ & P-value & $\begin{array}{c}\text { P-value } \\
\text { (MSI-H vs. } \\
\text { MSS/MSI-L) }\end{array}$ \\
\hline \multicolumn{7}{|c|}{ Age (mean) } \\
\hline$<55$ & $1(12.5)$ & $5(62.5)$ & $2(25.0)$ & $8 / 34(23.5)$ & \multirow[t]{3}{*}{0.496} & \multirow[t]{3}{*}{0.259} \\
\hline $55-64$ & $1(8.3)$ & $10(83.4)$ & $1(8.3)$ & $12 / 34(35.3)$ & & \\
\hline$>65$ & $2(14.3)$ & $7(50.0)$ & $5(35.7)$ & $14 / 34(41.2)$ & & \\
\hline \multicolumn{7}{|c|}{ Gender $(\mathrm{M} / \mathrm{F})$} \\
\hline M & $3(13.0)$ & $17(74.0)$ & $3(13.0)$ & 23/34 (67.6) & \multirow[t]{2}{*}{0.113} & \multirow[t]{2}{*}{0.050} \\
\hline $\mathrm{F}$ & $1(9.0)$ & $5(45.5)$ & $5(45.5)$ & $11 / 34(32.4)$ & & \\
\hline \multicolumn{7}{|c|}{ Borrmann's type } \\
\hline EGC & $0(0.0)$ & $7(100.0)$ & $0(0.0)$ & $7 / 34(20.6)$ & \multirow[t]{2}{*}{0.029} & \multirow[t]{2}{*}{0.160} \\
\hline $\mathrm{AGC}$ & $4(14.8)$ & $15(55.6)$ & $8(29.6)$ & 27/34 (79.4) & & \\
\hline \multicolumn{7}{|l|}{ Location } \\
\hline Antrum & $2(10.0)$ & $12(60.0)$ & $6(30.0)$ & $20 / 34(58.8)$ & \multirow[t]{4}{*}{0.617} & \multirow[t]{4}{*}{0.401} \\
\hline Body & $0(0.0)$ & $3(100.0)$ & $0(0.0)$ & 3/34 (8.8) & & \\
\hline Cardia & $0(0.0)$ & $1(50.0)$ & $1(50.0)$ & 2/34 ( 5.9) & & \\
\hline Mixed & $2(22.2)$ & $6(66.7)$ & $1(11.1)$ & $9 / 34(26.5)$ & & \\
\hline \multicolumn{7}{|c|}{ Differentiation } \\
\hline WD/MD & $0(0.0)$ & $10(83.3)$ & $2(16.7)$ & $12 / 34(35.3)$ & \multirow[t]{2}{*}{0.089} & \multirow[t]{2}{*}{0.402} \\
\hline PD & $4(18.2)$ & $12(54.5)$ & $6(27.3)$ & $22 / 34(64.7)$ & & \\
\hline \multicolumn{7}{|l|}{ LN spread } \\
\hline Absent & $1(9.1)$ & $10(90.9)$ & $0(0.0)$ & $11 / 34(32.4)$ & \multirow[t]{2}{*}{0.018} & \multirow[t]{2}{*}{0.027} \\
\hline Present & $3(13.0)$ & $12(52.2)$ & $8(34.8)$ & $23 / 34(67.6)$ & & \\
\hline \multicolumn{7}{|l|}{ Metastasis } \\
\hline Absent & $3(11.5)$ & $19(73.1)$ & $4(15.4)$ & $26 / 34(76.5)$ & \multirow[t]{2}{*}{0.116} & \multirow[t]{2}{*}{0.066} \\
\hline Present & $1(12.5)$ & $3(37.5)$ & $4(50.0)$ & $8 / 34(23.5)$ & & \\
\hline \multicolumn{7}{|c|}{ TNM stage } \\
\hline $\mathrm{I} / \mathrm{II}$ & $1(6.3)$ & $13(81.1)$ & $2(12.6)$ & $16 / 34(47.1)$ & \multirow[t]{2}{*}{0.163} & \multirow[t]{2}{*}{0.153} \\
\hline III/IV & $3(16.7)$ & $9(50.0)$ & $6(33.3)$ & $18 / 34(52.9)$ & & \\
\hline
\end{tabular}

WD, well differentiated; MD, moderately differentiated. Bold, statistically significant.

D17S520 and D17S855 $(32.4 \%, 11 / 34)$ and D3S1260 $(23.5 \%$, $8 / 34$ ) in the tumor samples. Fig. 2 shows the MSI frequencies from the 13 MS markers. The representative example of (A) a normal case and (B) the allelic shifts at the D17S855 (top) and D18S34 (bottom) loci are shown in Fig. 3.

Genotype-phenotype and clinicopathological associations. Clinicopathological variables of the GC cases were comparatively analyzed according to the MSI genotypes: MSI-H $(23.5 \%, 8 / 34)$, MSI-L $(64.7 \%, 22 / 34)$ and MSS $(11.8 \%, 4 / 34)$ Given the preponderance of evidence indicating that tumors with MSI-L are not biologically distinct from those that are MSS (17,18), we combined two subtypes of MSI (MSI-L/ MSS) into a MSI-negative (MSI-) classification to compare the clinical significance and prognostic value with a MSI-H group $\left(\mathrm{MSI}^{+}\right)$.

The prevalence of MSI revealed a significant difference in terms of gender in which MSS/MSI-L were primarily observed in males (males, $87.0 \%$ vs. females, $54.5 \%$ ), whereas
MSI-H was found at a significantly higher frequency in women (females, $45.5 \%$ vs. males, $13.3 \%$; $\mathrm{P}=0.050$ ). The difference in MSI status also showed a large discrimination with the status of lymph node (LN) metastasis. The prevalence of MSI-H was significantly higher in patients with $\mathrm{LN}$ metastasis than in those without ( $34.8 \%$ vs. $0 \%$, respectively; $\mathrm{P}=0.018$ ).

Most clinicopathological variables, including age, tumor location, Borrmann's type and histological differentiations were also closely related to the MSI genotype, although this association was not always statistically significant. Older patients $(62.5 \%, 5 / 8)$, antral location $(85 \%, 6 / 8)$, AGC cases $(100 \%, 8 / 8)$, and poorly differentiated (PD) tumors $(85 \%, 6 / 8)$ strongly emerged as MSI-H cases. A comparison of clinicopathological features according to the MSI status is shown in Table II.

Clinicopathological significance of MSI status on each MS locus. In order to further clarify critical MS markers 


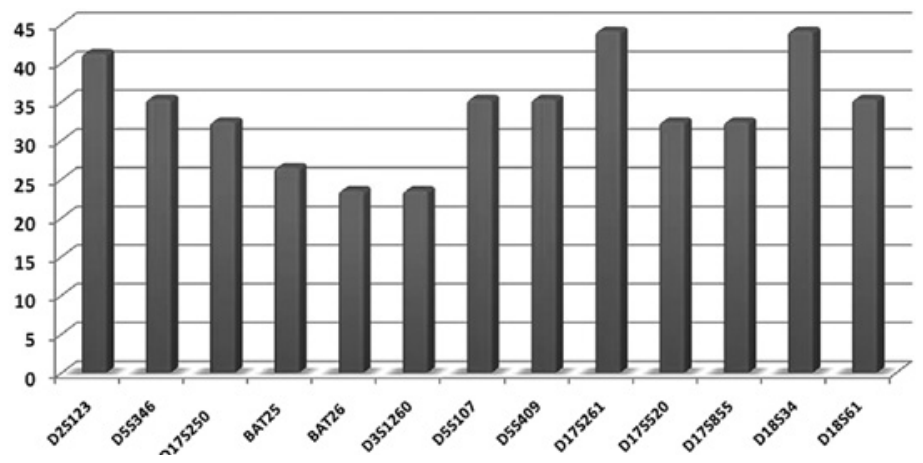

Figure 2. The frequency of MSI detected at 13 different MS markers from GC patients. The percentage of MSI was calculated by dividing the number of MSI at the specific MS marker by the number of informative cases.

A
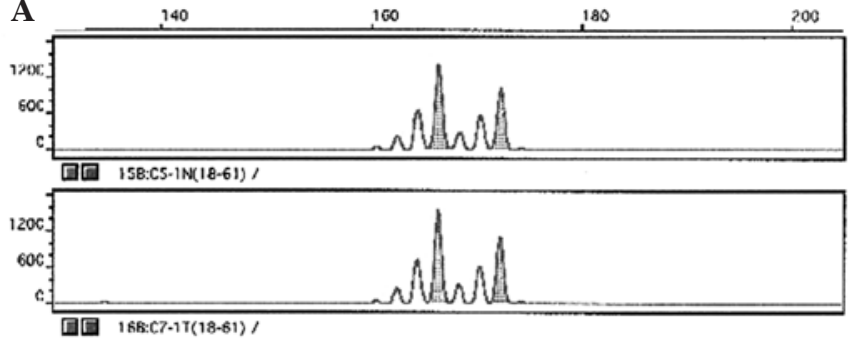

B
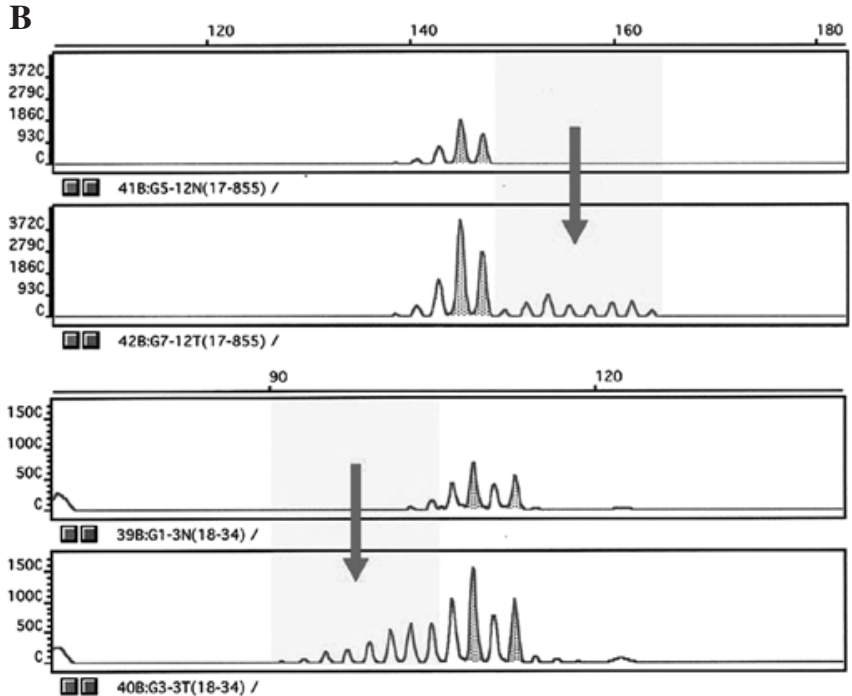

Figure 3. Examples of MSI analysis in GC cases. (A) MSS. (B) MSI analysis using the D17S855 (top) and D18S34 (bottom) markers revealed different allelic shift peaks (arrowhead) compared to those of the normal control DNA.

associated with GC progression, each MSI frequency from 13 different MS loci was compared to histological classifications and various tumor stages of GC.

The significant associations between MSI incidence and histological classifications of GC were identified. The incidence of MSI for the markers, D17S250 and D17S520, showed significantly higher frequencies in AGC than in EGC (100\% vs. $53.8 \%$, respectively; $\mathrm{P}=0.046$ ). Fig. $4 \mathrm{~A}$ represents the comparison of the MSI frequency between histological classifications and the 13 MS loci.

A significantly different association was also noted between tumor stages and MSI prevalence for the two
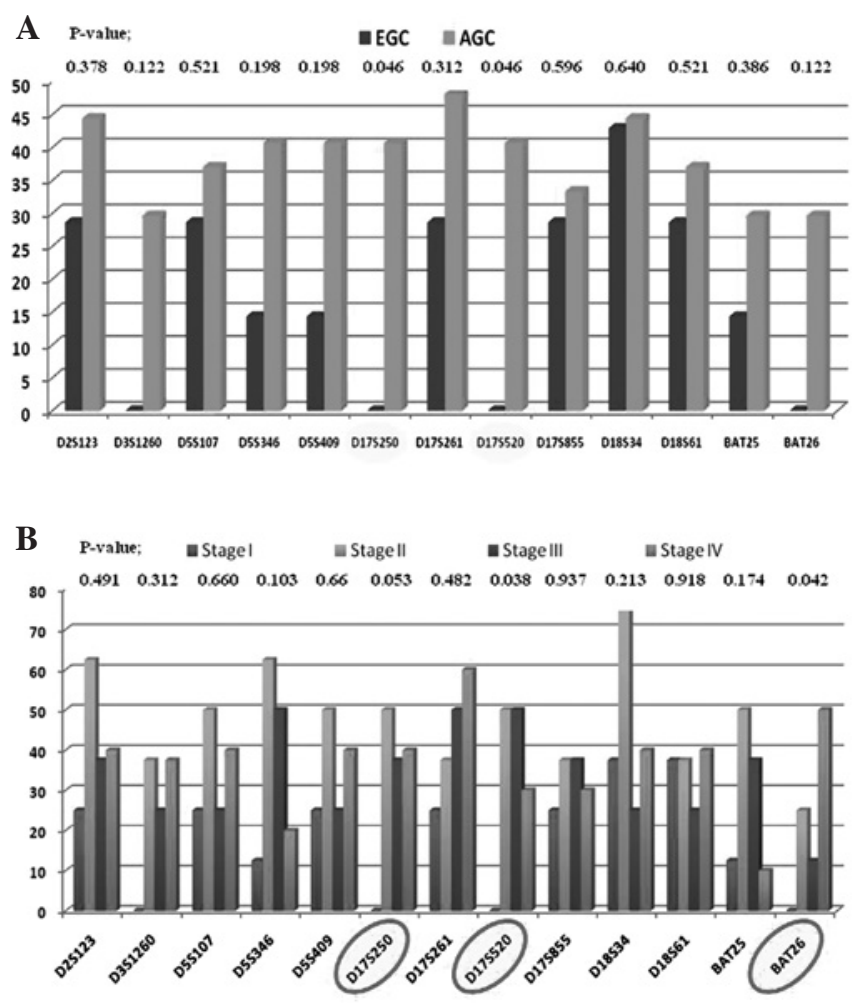

Figure 4. Comparison of MSI frequency on each locus by Borrmann's type and tumor stages. (A) Frequency of MSI between Borrmann's type on each locus in 34 GC cases. (B) Frequency of MSI among different tumor stages on 13 MS markers. The frequencies indicated refer to the proportion of $\mathrm{MSI}^{+}$ neoplasms on each locus.

markers, D17S520 and BAT26 ( $\mathrm{P}=0.038$ and 0.042 , respectively), indicating progressive accumulation of these loci during GC development. The frequency of various tumor stages detected with the different MS markers in GC cases is shown in Fig. 4B.

\section{Discussion}

Gastric cancer remains a leading cause of cancer mortality worldwide (1). During the last decade, numerous studies have described the potential of MSI as a molecular prognostic marker in GC (2-5). However, in absence of established criteria and methodology, the data on the prevalence and significance 
of MSI in GC are still not conclusive and literature on this field remains ambiguous.

In this study, we examined an additional 13 MS loci to assess the clinicopathological implication of MSI to identify the critical MS loci, which will facilitate the comparison of results from different studies. Our analysis demonstrated that a significant proportion of GC samples exhibited MS alteration in $88 \%$ of the patients, and $23.5 \%$ had the MSI-H phenotype.

In previous reports $(2,4,8,19)$, GC with MSI-H had a significantly higher frequency in older patients and women, and in antrally located and PD tumors, but a low incidence in patients with lymph node (LN) metastasis in comparison with MSI-L or MSS cases. In the current analysis, although not significant, MSI-H was somewhat more frequent in older patients, and was mainly found in the antrum and AGC patients, and exhibited a trend toward a more favorable prognosis in PD tumors.

Interestingly, MSI-H GCs were significantly associated with LN involvement in females. Previous reports considered the low frequency of LN metastasis to be an indication of good prognosis in MSI-H patients (20). However, in the analysis of Korean patients, the incidence of LN metastasis was more frequent in MSI-H tumors. Oki et al (7) noted that LN metastasis occurred frequently in MSI-H tumors, and a large degree of lymph vessel invasion was also observed in GC cases. Therefore, MSI cannot be regarded as a prognostic factor in GC patients. The high incidence of $\mathrm{LN}$ metastasis in MSI-H tumors was also reported in GC cases (21). Accordingly, it is unclear whether MSI is a prognostic or a predictive factor in GC. GCs with and without MSI-H appear to represent distinctive pathways of carcinogenesis (22). Future integrative applications with a larger series and expanded cases are warranted to verify the clinical impact of MSI on this outcome for GC patients.

Even though the data consistently support the possible correlation between the degree of the MSI and clinical outcome $(2,23,24)$, there is no consistent consensus regarding the MSI genotypes. Thus, widely variable results on the frequency and definition of MSI in GC have been reported depending on the type and number of MS markers used (2). In this study, we therefore assessed an additional 8 dinucleotide repeat MS loci to further clarify the critical MS markers in GC. The highest frequency of MSI was simultaneously noted at the DI7S261 and DI8S34 (44.1\%, 15/34) loci; this is superior to the NCI panels of MS markers. The DCC gene at the D18S34 locus is thought to be one of the prime target genes on 18q, and its hyper-methylation or reduced expression in GC has been described in previous studies (23-25), indicating that the D18S34 locus is critically involved in initiating gastric carcinogenesis and may be a valuable MS marker for GC screening.

The TNM stage has been considered to be the most important prognostic determinant in GC (9). To clarify the critical MSI loci in relation to GC progression, each MSI frequency from 13 different loci was compared to various tumor stages. We identified significantly different associations between tumor stages and MSI prevalence for the two markers, D17S520 and BAT26 ( $\mathrm{P}=0.038$ and 0.042 , respectively), and a borderline significance for the D17S250 locus ( $\mathrm{P}=0.053)$, indicating that these markers may be another independent genetic determinant with $\mathrm{GC}$ prognostic value. Moreover, the D17S250 and D17S520 markers exhibited a significantly higher percentage of MSI in AGC than in EGC patients in terms of histological classifications of $\mathrm{GC}(\mathrm{P}=0.046$ and 0.046 , respectively). The D17S520 marker has thus far not been documented in GC. However, the high frequency of MSI or the loss of heterozygosity at this locus has been established in different cancer types. Uchino et al (25) reported the high frequency of MSI at D17S520 (41\%) in oral carcinoma, and others have demonstrated sequence deletions at D17S520 (52\%) in squamous cell carcinomas of the lung (26). These findings support our hypothesis that D17\$520 may be a potential MSI marker in GC and may be useful for predicting disease progression and prognosis.

In this study, we confirm previous findings that GC with MSI-H exhibits specific clinicopathological characteristics. Moreover, we identify the novel MS markers D17S261 and D18S34 as screening MSI loci, and D17S520 as having a role in predicting a poor prognosis in GC. Future investigations are expected to validate these MS loci in a translational application in the GC field aiming to predict responses to treatments or outcomes, and to eventually use them as therapeutic targets.

\section{Acknowledgements}

This study was financially supported by the research fund of Korea Nazarene University in 2011.

\section{References}

1. Parkin DM, Pisani P and Ferlay J: Global cancer statistics. CA Cancer J Clin 49: 33-64, 1999.

2. Bacani J, Zwingerman R, di Nicola N, Spencer S, Wegrynowski T, Mitchell K, Hay K, Redston M, Holowaty E, Huntsman D, Pollett A, Riddell R and Gallinger S: Tumor microsatellite instability in early onset gastric cancer. J Mol Diagn 7: 465-477, 2005.

3. Leite M, Corso G, Sousa S, Milanezi F, Afonso LP, Henrique R, Soares JM, Castedo S, Carneiro F, Roviello F, Oliveira C and Seruca R: MSI phenotype and MMR alterations in familial and sporadic gastric cancer. Int J Cancer 128: 1606-1613, 2010.

4. Seo HM, Chang YS, Joo SH, Kim YW, Park YK, Hong SW and Lee SH: Clinicopathologic characteristics and outcomes of gastric cancers with the MSI-H phenotype. J Surg Oncol 99: 143-147, 2009.

5. Lee HS, Choi SI, Lee HK, Kim HS, Yang HK, Kang GH, Kim YI, Lee BL and Kim WH: Distinct clinical features and outcomes of gastric cancers with microsatellite instability. Mod Pathol 15: 632-640, 2002.

6. Vo AT, Zhu F, Wu X, Yuan F, Gao Y, Gu L, Li GM, Lee TH and Her C: hMRE11 deficiency leads to microsatellite instability and defective DNA mismatch repair. EMBO Rep 6: 438-444, 2005.

7. Oki E, Kakeji Y, Zhao Y, Yoshida R, Ando K, Masuda T, Ohgaki K, Morita M and Maehara Y: Chemosensitivity and survival in gastric cancer patients with microsatellite instability. Ann Surg Oncol 16: 2510-2515, 2009.

8. Umar A, Boland CR, Terdiman JP, Syngal S, de la Chapelle A, Rüschoff J, Fishel R, Lindor NM, Burgart LJ, Hamelin R, Hamilton SR, Hiatt RA, Jass J, Lindblom A, Lynch HT, Peltomaki P, Ramsey SD, Rodriguez-Bigas MA, Vasen HF, Hawk ET, Barrett JC, Freedman AN and Srivastava S: Revised Bethesda Guidelines for hereditary nonpolyposis colorectal cancer (Lynch syndrome) and microsatellite instability. J Natl Cancer Inst 96: 261-268, 2004.

9. Xicola RM, Llor X, Pons E, Castells A, Alenda C, Piñol V, Andreu M, Castellví-Bel S, Payá A, Jover R, Bessa X, Girós A, Duque JM, Nicolás-Pérez D, Garcia AM, Rigau J and Gassull MA: Gastrointestinal Oncology Group of the Spanish Gastroenterological Association: Performance of different microsatellite marker panels for detection of mismatch repair-deficient colorectal tumors. J Natl Cancer Inst 99: 244-252, 2007. 
10. Bocker T, Diermann J, Friedl W, Gebert J, Holinski-Feder E, Karner-Hanusch J, von Knebel-Doeberitz M, Koelble $\mathrm{K}$, Moeslein G, Schackert HK, Wirtz HC, Fishel R and Rüschoff J: Microsatellite instability analysis: a multicenter study for reliability and quality control. Cancer Res 57: 4739-4743, 1997.

11. Dietmaier W, Wallinger S, Bocker T, Kullmann F, Fishel R and Rüschoff J: Diagnostic microsatellite instability: definition and correlation with mismatch repair protein expression. Cancer Res 57: 4749-4756, 1997.

12. Kang JU, Koo SH, Kwon KC, Park JW and Kim JM: Gain at chromosomal region 5p15.33, containing TERT, is the most frequent genetic event in early stages of non-small cell lung cancer. Cancer Genet Cytogenet 182: 1-11, 2008.

13. Bovo D, Rugge M and Shiao YH: Origin of spurious multiple bands in the amplification of microsatellite sequences. J Mol Pathol 52 50-51, 1999.

14. Hatch SB, Lightfoot HM Jr, Garwacki CP, Moore DT, Calvo BF, Woosley JT, Sciarrotta J, Funkhouser WK and Farber RA: Microsatellite instability testing in colorectal carcinoma: choice of markers affects sensitivity of detection of mismatch repairdeficient tumors. Clin Cancer Res 11: 2180-2187, 2005.

15. Starostik P, Greiner A, Schwarz S, Patzner J, Schultz A and Müller-Hermelink HK: The role of microsatellite instability in gastric low- and high-grade lymphoma development. Am J Pathol 157: 1129-1136, 2000

16. Kim HS, Lee BL, Woo DK, Bae SI and Kim WH: Assessment of markers for the identification of microsatellite instability phenotype in gastric neoplasms. Cancer Lett 164: 61-68, 2001.

17. Jass JR, Young J and Leggett BA: Biological significance of microsatellite instability-low (MSI-L) status in colorectal tumors. Am J Pathol 158: 779-781, 2001.

18. Wu CW, Chen GD, Jiang KC, Li AF, Chi CW, Lo SS and Chen JY: A genome-wide study of microsatellite instability in advanced gastric carcinoma. Cancer 92: 92-101, 2001.

19. Elsaleh H, Joseph D, Grieu F, Zeps N, Spry N and Iacopetta B: Association of tumour site and sex with survival benefit from adjuvant chemotherapy in colorectal cancer. Lancet 355: 1745-1750, 2000
20. Kim YH, Song SY, Kwon YD, Kim DS, Chun HK and Rhee JC: Microsatellite instable double primary cancers of the colorectum and stomach exhibit less favorable outcome. World J Gastroenterol 11: 3998-4002, 2005.

21. Gu M, Kim D, Bae Y, Choi J, Kim S and Song S: Analysis of microsatellite instability, protein expression and methylation status of hMLH1 and hMSH2 genes in gastric carcinomas. Hepatogastroenterology 56: 899-904, 2009.

22. Miyamoto $\mathrm{N}$, Yamamoto $\mathrm{H}$, Taniguchi $\mathrm{H}$, Miyamoto $\mathrm{C}$, Oki M, Adachi Y, Imai K and Shinomura Y: Differential expression of angiogenesis-related genes in human gastric cancers with and those without high-frequency microsatellite instability. Cancer Lett 254: 42-53, 2007.

23. Hibi K, Sakata M, Sakuraba K, Kitamura YH, Shirahata A, Goto T, Mizukami H, Saito M, Ishibashi K, Kigawa G, Nemoto $\mathrm{H}$ and Sanada Y: Methylation of the DCC gene is lost in advanced gastric cancer. Anticancer Res 30: 107-109, 2010

24. Falchetti M, Saieva C, Lupi R, Masala G, Rizzolo P, Zanna I, Ceccarelli K, Sera F, Mariani-Costantini R, Nesi G, Palli D and Ottini L: Gastric cancer with high-level microsatellite instability: target gene mutations, clinicopathologic features, and long-term survival. Hum Pathol 39: 925-932, 2008.

25. Uchino S, Tsuda H, Noguchi M, Yokota J, Terada M, Saito T, Kobayashi M, Sugimura T and Hirohashi S: Frequent loss of heterozygosity at the DCC locus in gastric cancer. Cancer Res 52: 3099-3102, 1992.

26. Chmara M, Wozniak A, Ochman K, Kobierska G, Dziadziuszko R, Sosinska-Mielcarek K, Jassem E, Skokowski J, Jassem J and Limon J: Loss of heterozygosity at chromosomes $3 \mathrm{p}$ and $17 \mathrm{p}$ in primary non-small cell lung cancer. Anticancer Res 24: 4259-4263, 2004. 